\title{
Reproducibility of exhaled nitric oxide measurements in healthy and asthmatic adults and children
}

\author{
S.A. Kharitonov, F. Gonio, C. Kelly, S. Meah, P.J. Barnes
}

Reproducibility of exhaled nitric oxide measurements in healthy and asthmatic adults and children. S.A. Kharitonov, F. Gonio, C. Kelly, S. Meah, P.J. Barnes. (C) ERS Journals Ltd 2003.

ABSTRACT: Airway inflammation in asthma is not measured routinely in clinical practice. Fractional exhaled nitric oxide (FENO), a marker of airway inflammation, is increasingly used as an outcome measure in asthma intervention studies and yet the reproducibility of FENO measurements is unknown.

The reproducibility, day-to-day, diurnal variation and perception of standardised FENO measurements were examined in 59 subjects (40 children aged 7-13 yrs and 19 adults aged $18-60$ yrs), both healthy $(n=30)$ and with mild $(n=29)$ asthma. FENO was measured on five consecutive days (four measurements on the same day) for adults and twice on the same day for children.

The coefficient of reproducibility expressed as the mean pooled standard deviation ( $\mathrm{n}=59$, 675 estimations) was 2.11 parts per billion (ppb) and intraclass correlation coefficient was 0.99 in both children and adults. FENO was significantly higher in asthma subjects $(32.3 \mathrm{ppb})$ than in healthy subjects $(16.3 \mathrm{ppb})$. There was no diurnal or day-to-day variation, or a learning effect, as the result of FENO measurements were identical at results of the beginning and at the end of the study.

It was concluded that fractional exhaled nitric oxide measurements are simple, reproducible, free from diurnal and day-to-day variation, and acceptable by both healthy and asthmatic adults and children, as a part of their routine visit to a physician. Eur Respir J 2003; 21: 433-438.
Dept of Thoracic Medicine, National Heart and Lung Institute, Faculty of Medicine, Imperial College of Science, Technology and Medicine, Royal Brompton and Harefield NHS Trust, London, UK.

Correspondence: S.A. Kharitonov, Dept of Thoracic Medicine, National Heart \& Lung Institute, Imperial College, Dovehouse Street, London, SW3 6LY, UK.

Fax:02073518126

E-mail: s.kharitonov@imperial.ac.uk

Keywords: Asthma, exhaled nitric oxide, fractional exhaled nitric oxide measurements

Received: July 242002

Accepted after revision: November 12 2002

This study was supported by Aerocrine $\mathrm{AB}$, Stockholm, Sweden.
Asthma is an inflammatory disease, yet airway inflammation is not measured directly and routinely in clinical practice [1]. This makes management of asthma difficult, because it is based on indirect measurements of airway inflammation, such as symptoms and lung function. Symptoms may not accurately reflect the extent of underlying inflammation due to differences in perception, and lung function tests may have little room for improvement in mild asthma. None of these parameters is able to distinguish the effect of different doses of inhaled corticosteroids and both may be affected by bronchodilators. The latter is particularly important because of a recent trend towards use of lower doses of inhaled corticosteroids in combination with long-acting $\beta_{2}$-agonists.

Current invasive (bronchoscopy), or semi-invasive (sputum induction) direct methods to measure airway inflammation are difficult to use repeatedly in clinical practice. The use of sputum induction is limited by its pro-inflammatory effect [2], and a considerable bronchospasm has been reported during sputum induction in moderate $(14 \%)$ and severe $(25 \%)$ asthma, as a result of the procedure [3].

There has been an explosion of research into exhaled nitric oxide (NO) since levels were found to be increased in asthma [1, 4]. Standardised $[5,6]$ measurements of fractional exhaled NO (FENO) provide a completely noninvasive means of monitoring airway inflammation and anti-inflammatory treatment in asthma [1], including a dose-dependent onset and duration of action of inhaled corticosteroids [7]. It may be useful in patients using fixed combination inhalers (corticosteroids and longacting $\beta_{2}$-agonist) to ensure that inflammation is controlled, as this may be difficult to assess from symptoms when a longacting bronchodilator is taken.

The changes in serial FENO, as a loss-of-control-marker [8], have higher predictive values for diagnosing the deterioration of asthma [9] than does single measurements [10, 11].

It can be argued, however, that these changes in FENO may be due to measurement error and/or the natural variability of airway inflammation over time. Therefore, design and interpretation of clinical studies in asthma and the use of FENO in routine clinical practice depends greatly on the reproducibility and the safety of FENO measurements. Reproducibility of FENO measurements was studied by several groups, but either the statistical analysis was inappropriate (correlation coefficient) [12], or exhalation flow rate was either not registered [13], or was different from the American Thoracic Society (ATS) recommendations [14].

Because of uncertainty regarding the reproducibility and the safety of standardised FENO measurements made in accordance with the ATS recommendations [5], these issues were examined in asthmatic and healthy subjects, including both adults and children.

\section{Methods}

\section{Subjects and protocol}

Sixty nonsmoking subjects (26 males and 34 females, with an adult mean \pm SD age of $35.6 \pm 9.39$ yrs and children $10.7 \pm$ $1.79 \mathrm{yrs}$ ) were recruited for this prospective, open, single-centre 
study, performed in accordance with the guidelines of Good Clinical Practice. The healthy subjects (10 adults and 20 children) had neither atopy nor history of asthma or other diseases, and normal lung function. All patients were diagnosed with atopic mild steroid-naive asthma (10 adults and 20 children). The asthmatic subjects had no history of asthma exacerbation or upper respiratory infection in the preceding 4 weeks, and their lung function was normal (forced expiratory volume in one second (FEV1 101 $\pm 3 \%$ pred and $98 \pm 4 \%$ pred, for adults and children, respectively). Subjects were not allowed to eat any food within $1 \mathrm{~h}$ prior to the exhalation session, but could drink water (water intake was recorded). There was no change in asthma medication during the study.

Procedures on the first visit included information about the study and obtaining informed consent from adults and the parents of children, medical and asthma history, physical examination, allergen skin testing, baseline spirometry and practice of exhalation procedure with the NO analyser for measuring exhaled NO.

Children underwent two FENO measurements consisting of sessions of three measurements in each session, the first between 09:00-10:00 $\mathrm{h}$ and the second between 14:00-15:00 $\mathrm{h}$ with a standard lunch between 12:00-13:00 h. Adults had their FENO measured once on five consecutive days between 09:00-10:00 h during visits 1, 2, 3, and 4, and during the last visit (fifth) FENO was measured four times, between 09:00-10:00 h, 11:00-12:00 h, 14:00-15:00 $\mathrm{h}$, and 16:00-17:00 $\mathrm{h}$ with a standard lunch between 12:00-13:00 h. Children and/or their parents and adults were asked to report any unpleasant events associated with the measurement sessions, and questions regarding their subjective experience of the FENO measurements were asked at the end of the study. The study was approved by the Ethics Committee of the Royal Brompton and Harefield NHS Trust.

\section{Measurements of fractional exhaled nitric oxide}

FENO was measured according to the ATS recom-

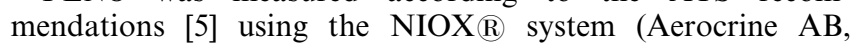
Stockholm, Sweden). Any exhalation, which did not meet the ATS requirements, was not accepted by the NIOX $\AA$ system and the subjects were asked to perform a new exhalation manoeuvre. At each session three correctly executed exhalations were recorded.

\section{Statistical methods}

Reproducibility of FENO measurements was assessed in three different ways: 1) by the Bland and Altman analysis, which is used when the measurements are on the same scale; 2) by means of the intraclass correlation coefficient (ICC), a dimensionless statistic that describes the reproducibility of repeated measurements in the same population; 3) by the pooled SD, as the final measure of repeatability for all studied healthy and asthmatic subjects. Bland-Altman analysis was also applied to study diurnal variation in adults using the first and last measurement during day 5 . In children the morning and the afternoon sessions were compared. The "learning effect" was studied in adults by comparing the morning sessions on day 1 and day 5. Day-to-day variability, influence of asthma, sex, height, weight, age and food intake on the FENO value, and the safety of FENO measurements performed under conditions, which were close to a routine clinical setting, were examined.

The value of ICC is bounded by 0 and 1 , and in a stable population ICC values in excess of 0.6 are thought to be clinically significant, and those $<0.6$ are probably not [15]. The authors decided to choose an ICC value of $>0.75$ [3] to represent a clinically useful method, as this cut-off level was used recently in a reproducibility study of another approach to monitor asthma, i.e. sputum induction [3].

Comparisons of FENO in healthy and asthmatic children and adults were performed using mean values of FENO measurements from all sessions. Descriptive parametric statistical methods were used to describe and summarise the results from the study. Mean values were presented as mean \pm SD. Between-group significance tests were performed using twosample t-tests with due correction according to Satterthwaite [16], for degrees of freedom when variances were inhomogeneous according to the Levene [17] test, and within group changes were analysed using paired samples t-test. Mean individual FENO values were correlated to sex, age, height, weight, and food intake using Pearson correlation analyses. The Kolmogorov-Smirnov test of normality of data was applied. Sample size calculations were made by using the following formulae.

One-sample (one treatment) trials:

$$
\mathrm{n}=\frac{\sigma^{2}(\mathrm{t} 1-\alpha / 2+\mathrm{t} 1-\beta)^{2}}{\delta^{2}}
$$

Two-sample (treatment versus placebo) trials:

$$
\mathrm{n}_{\text {group }}=\frac{2 \sigma^{2}(\mathrm{t} 1-\alpha / 2+\mathrm{t} 1-\beta)^{2}}{\delta^{2}}
$$

where $\delta^{2}$ is effect size expressed as relative change (\%), $\sigma^{2}$ is SD of relative change $(\%)$, and $t$ is the $t$-test.

Statistics were presented using both complete data or sometimes with outliers excluded. An outlier was defined as a value outside \pm SD from the mean. FENO values of one of the adult asthmatic patients (1.13) were not included in the final analysis because the levels were well above 2SD (110-160 parts per billion (ppb)) of the studied population. This patient with mild stable atopic asthma and characteristically high FENO levels, which may become even higher during asthma exacerbations, has been seen in the authors' clinic for several years. Other research groups [18] have also reported patients with very high FENO values between $150-300 \mathrm{ppb}$, which suggests that there is a small number of patients with difficult to explain high FENO values.

\section{Results}

\section{Patient enrolment and effect of demographic and other factors on fractional exhaled nitric oxide}

The majority ( $89 \%$ ) of adults and $78 \%$ children completed the study between September-December 2000, hence outside the grass pollen season. In all, 675 exhalations (of 696 theoretically accessible exhalations) made during 229 measurements (of 232 theoretically accessible sessions) were performed and analysed. At three sessions (21 exhalations) the NIOX $\AA$ device was out of order.

Patients with asthma (adults and children) had a higher FENO $(32.3 \pm 25.9 \mathrm{ppb})$ than healthy subjects $(16.3 \pm 8.4 \mathrm{ppb}$; $\mathrm{p}<0.005)$. When analysed separately, adults with asthma had higher FENO (48.8 $\pm 27.2 \mathrm{ppb})$ than healthy adults $(17.8 \pm 6.8 \mathrm{ppb}$; $\mathrm{p}<0.010)$. Children with asthma had a borderline significantly higher FENO (24.9 $\pm 22.3 \mathrm{ppb})$ than healthy children (15.6 $\pm 9.2 \mathrm{ppb}$; $\mathrm{p}<0.096$ ).

Healthy adult females $(n=7)$ had significantly lower FENO levels $(14.85 \pm 3.34 \mathrm{ppb})$ than healthy males $(\mathrm{n}=3,24.6 \pm 8.59 \mathrm{ppb}$; $\mathrm{p}<0.03$ ). No correlations were found between FENO and duration of asthma, season, food intake, body weight or height. There was no significant difference in FENO between the subjects who consumed water before the measurements $(41.24 \pm 57.40 \mathrm{ppb})$ 
Table 1.-Reproducibility of fractional exhaled nitric oxide measurements

\begin{tabular}{|c|c|c|c|c|c|c|c|c|}
\hline \multirow[t]{2}{*}{ Subjects } & \multicolumn{4}{|c|}{ Visits } & \multicolumn{4}{|c|}{ Visit $5^{\#} \mathrm{~h}$} \\
\hline & 1 & 2 & 3 & 4 & 09:00-10:00 & $11: 00-12: 00$ & $14: 00-15: 00$ & $16: 00-17: 00$ \\
\hline \multicolumn{9}{|l|}{ Healthy } \\
\hline $\begin{array}{l}\text { Adults } \\
\text { Children }\end{array}$ & $17.0 \pm 1.61$ & $17.4 \pm 2.28$ & $18.1 \pm 2.81$ & $16.8 \pm 1.65$ & $\begin{array}{l}18.5 \pm 2.15 \\
15.2 \pm 1.96\end{array}$ & $17.5 \pm 2.01$ & $\begin{array}{l}17.2 \pm 2.08 \\
15.9 \pm 2.18\end{array}$ & $15.8 \pm 1.88$ \\
\hline Asthma & & & & & & & & \\
\hline $\begin{array}{l}\text { Adults } \\
\text { Children }\end{array}$ & $54.2 \pm 11.01$ & $52.5 \pm 10.77$ & $49.5 \pm 9.38$ & $47.9 \pm 7.93$ & $\begin{array}{l}46.5 \pm 8.65 \\
24.3 \pm 4.58\end{array}$ & $48.3 \pm 8.93$ & $\begin{array}{l}45.1 \pm 8.33 \\
25.4 \pm 5.38\end{array}$ & $45.8 \pm 9.22$ \\
\hline
\end{tabular}

Data are presented as mean \pm SEM. ${ }^{\#}$ : visit 5 in adults and visit 1 in children.

and subjects who did not consume water $(37.83 \pm 49.05 \mathrm{ppb}$, $\mathrm{p}>0.05)$.

\section{Repeatability and reproducibility}

Data was approximately normally distributed (KolmogorovSmirnov test, $\mathrm{p}>0.20$ ). The mean pooled SD of all measurements was $2.1 \pm 1.25 \mathrm{ppb}$.

FENO measurements made at different visits and time points were highly reproducible throughout the study (table 1), and there was no significant diurnal or day-to-day variation (fig. 1) of FENO in adults and no diurnal variation in children. BlandAltman analysis of distance from session means using all 675 FENO measurements yielded Bland-Altman "limits of agreement" of $\pm 4.01 \mathrm{ppb}$ (i.e. $2 \times \mathrm{SD}$ ). After removal of outliers (i.e. 38 measurements $>2$ SD from session mean, $2 \times 2.01=4.01 \mathrm{ppb}$ ) the repeatability of the FENO measurements as measured by the Bland-Altman limits of agreement was $\pm 2.92 \mathrm{ppb}$ (fig. 2).

In order to assess the possibility of reducing the number of measurements from three to two per session, the precision of measurements using one and two measurements per session was analysed. The FENO value from each one of the three measurements in a session was compared with the mean FENO value from all the three measurements. The difference in the worst case was $0.28 \pm 5.8 \mathrm{ppb}(95 \%$ confidence interval (CI)). When the mean FENO from two measurements was compared with the mean FENO value from all three measurements, the worst case difference was $-0.26 \pm 2.92 \mathrm{ppb}(95 \% \mathrm{CI})$ (table 2). All ICC values found were above the chosen accepted limit of 0.75 . In fact all ICC values were $\geqslant 0.90$ (table 3 ).

There was no "learning effect", as there was no statistically

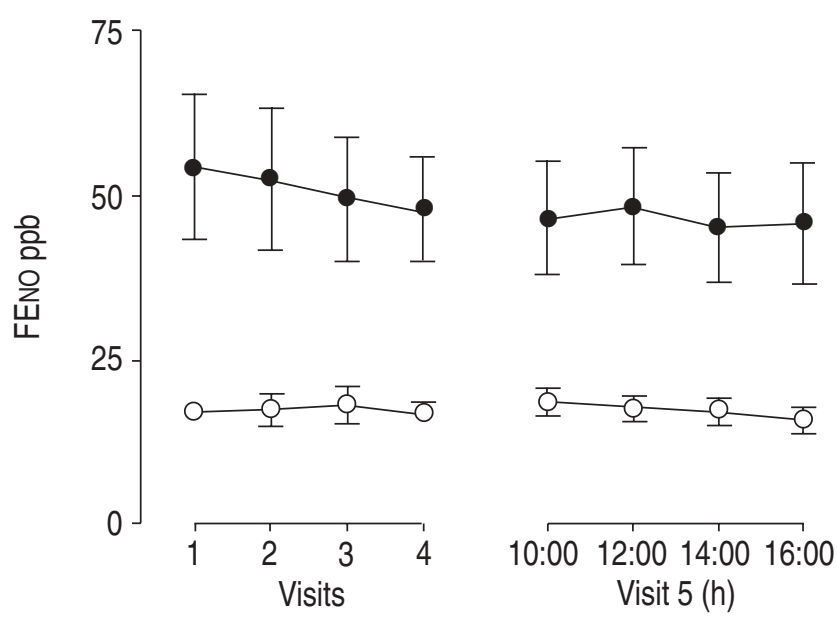

Fig. 1. - Means \pm SEM for fractional exhaled nitric oxide (FENO) in healthy $(\bigcirc)$ and asthmatic $(\bullet)$ adult subjects during successive sessions. ppb: parts per billion.

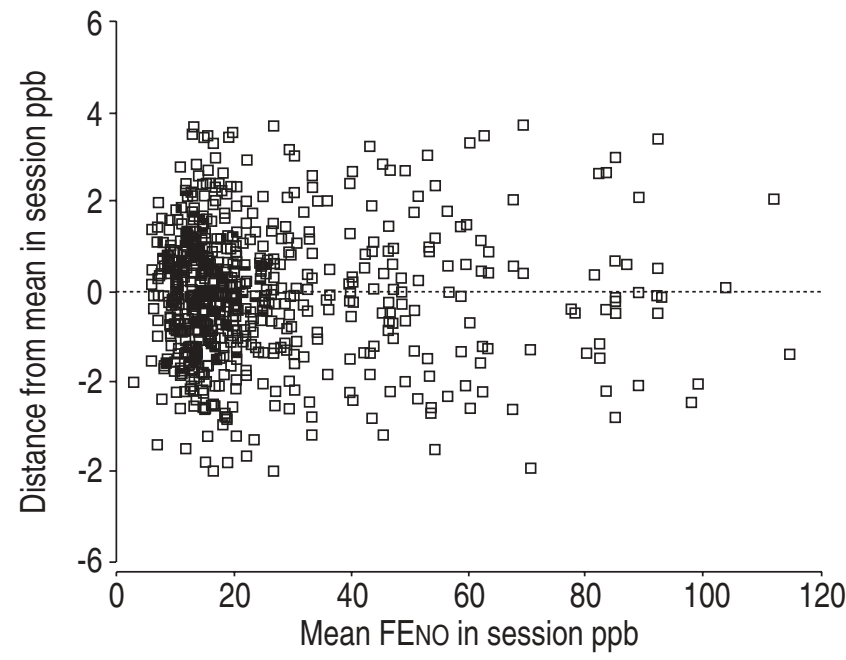

Fig. 2.-Bland-Altman analysis for the repeatability of fractional exhaled nitric oxide (FENO) values ( $n=637$ measurements). ppb: parts per billion.

significant difference between the FENO measurements made at the beginning and at the end of the study. Morning measurements during the first and last day did not differ significantly $(\mathrm{p}=0.138)$. The mean difference was $2.58 \mathrm{ppb}$. The upper limit of agreement was 16.64 and the lower limit $-11.48 \mathrm{ppb}$ in a Bland-Altman analysis. Sample size calculations based on the data from adult asthmatic patients for one and two clinical samples are presented in figure 3 .

\section{Patients perception of fractional exhaled nitric oxide measurements with NIOX $\mathbb{R}$}

The use of the NIOX $\AA$ system was safe throughout the study, and there were no adverse incidents recorded. The majority of the subjects found FENO measurements easy to perform, simple and potentially acceptable for use in routine clinical practice (table 4 ).

\section{Discussion}

It has been demonstrated that standardised FENO measure-

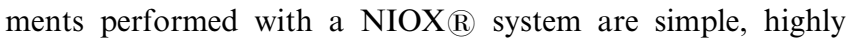
reproducible (pooled $\mathrm{SD}=2.11 \mathrm{ppb}$ and $\mathrm{ICC}=0.99$ ), free from diurnal and day-to-day variation and acceptable by healthy and asthmatic adults and children as a part of their routine visit to a physician.

Airway inflammation in asthma has been shown to exhibit considerable biological variability, yet it is not measured directly and routinely in clinical practice. This makes asthma 
Table 2. - Mean distance from session mean of fractional exhaled nitric oxide (FENO) measured during one or two exhalations in studied population groups

\begin{tabular}{|c|c|c|c|c|}
\hline \multirow[t]{2}{*}{ Subjects } & \multicolumn{2}{|c|}{$\begin{array}{l}\text { Difference between FENO of } \\
\text { single exhalation and session } \\
\text { mean (three exhalations) ppb }\end{array}$} & \multicolumn{2}{|c|}{$\begin{array}{c}\text { Difference between mean FENO of } \\
\text { two exhalations and session } \\
\text { mean (three exhalations) ppb }\end{array}$} \\
\hline & $\mathrm{n}$ & Difference $\pm S D$ & $\mathrm{n}$ & Difference \pm SD \\
\hline \multicolumn{5}{|l|}{ Healthy adults } \\
\hline FENO 1-FENO M & 75 & $0.15 \pm 1.52$ & 75 & $-0.10 \pm 0.64$ \\
\hline FENO 2-FENO M & 75 & $-0.34 \pm 1.18$ & 74 & $0.18 \pm 0.59$ \\
\hline FENO 3-FENO M & 74 & $0.20 \pm 1.30$ & 74 & $-0.08 \pm 0.77$ \\
\hline \multicolumn{5}{|l|}{ Healthy children } \\
\hline FENO 1-FENO M & 40 & $0.32 \pm 2.17$ & 40 & $0.03 \pm 0.87$ \\
\hline FENO 2-FENO M & 40 & $-0.26 \pm 1.46$ & 38 & $0.12 \pm 0.75$ \\
\hline FENO 3-FENO M & 38 & $-0.07 \pm 1.78$ & 38 & $-0.15 \pm 1.11$ \\
\hline \multicolumn{5}{|l|}{ Asthma adults } \\
\hline FENO 1-FENO M & 70 & $0.28 \pm 2.90$ & 70 & $-0.07 \pm 1.19$ \\
\hline FENO 2-FENO M & 70 & $-0.42 \pm 2.27$ & 69 & $0.21 \pm 1.14$ \\
\hline FENO 3-FENO M & 69 & $0.13 \pm 2.39$ & 69 & $-0.14 \pm 1.46$ \\
\hline \multicolumn{5}{|l|}{ Asthma children } \\
\hline FENO 1-FENO M & 40 & $0.31 \pm 1.80$ & 40 & $-0.21 \pm 1.22$ \\
\hline FENO 2-FENO M & 40 & $-0.72 \pm 2.11$ & 40 & $0.36 \pm 1.06$ \\
\hline FENO 3-FENO M & 40 & $0.42 \pm 2.44$ & 40 & $-0.15 \pm 0.90$ \\
\hline
\end{tabular}

FENO 1, 2, 3: FENO measured at the first, second and third exhalation; FENO M: mean FENO from all three exhalations in a session; FENO M 1 and 2 or 1 and 3 or 2 and 3: mean FENO of measurements 1 and 2 or 1 and 3 or 2 and 3, respectively; ppb: parts per billion.

Table 3. - Statistical comparison of the reproducibility of fractional exhaled nitric oxide (FENO) measurements between first and second versus first and fourth and morning versus afternoon visits

\begin{tabular}{lccc}
\hline Subjects & \multicolumn{2}{c}{ Visits } & Visit $5^{\#}$ \\
\cline { 2 - 3 } & 1 versus 2 & 1 versus 4 & $09: 00-10: 00 \mathrm{~h}$ versus 14:00-15:00 h \\
\hline $\begin{array}{l}\text { Healthy } \\
\quad \text { Adults }\end{array}$ & $0.94(0.77-0.99)$ & $0.94(0.74-0.98)$ & $0.98(0.91-0.99)$ \\
$\quad$ Children & & & $0.99(0.98-0.996)$ \\
Asthma & $0.94(0.75-0.99)$ & $0.90(0.57-0.98)$ & $0.99(0.98-0.999)$ \\
$\quad$ Adults & & & $0.99(0.98-0.996)$ \\
\hline
\end{tabular}

Data are presented as intraclass correlation coefficient means and 95\% confidence intervals. ${ }^{*}$ : visit 5 in adults and visit 1 in children.

monitoring and its anti-inflammatory treatment difficult. Several approaches are currently used to measure airway inflammation in asthma. They are, however, either invasive or semi-invasive (bronchoscopy and sputum induction), or less direct (provocative concentration causing a $20 \%$ fall in the FEV1 (PC20) and lung function), or may be affected by the patient's perception or bronchodilators (asthma symptoms). The reproducibility of these approaches is also variable.

Bronchial hyperreactivity test (PC20) is noninvasive and reasonably reproducible (ICC for PC20 methacholine 0.74 [4] and 0.94 [19]).

Bronchial biopsy, sputum induction and bronchial hyperreactivity tests may only be performed in specialised centres, are costly and time consuming, and cannot be used in patients with severe asthma or in small children. It is unlikely that any of these methods of airway inflammation assessment will be used in routine clinical practice.

FEV1 is the most reproducible indicator of airway inflammation in asthma. ICC values between 0.87 [20] and 0.93 [4] have been shown for the measurements made in specialised lung function (LF) laboratories, and coefficient of variation of $3 \%$ for FEV1 and forced vital capacity can be achieved by trained research workers [21]. Conversely, repeated FEV1 measurements made in patients at the primary care, by either trained or untrained physicians, had significantly lower sensitivity $(41 \%$ of the LF laboratory values as the standard) and a higher falsenegative rate $(59 \%)$ [22]. The reproducibility of peak expiratory flow (PEF) may also be very low, and there are reports that some patients may manipulate the PEF meter in a way that could repeatedly produce clinically significant changes in readings [23]. Both, home recording of PEF and symptom diaries are easily faked and are generally unreliable in both adults [24] and children [25].

In addition, symptoms may not accurately reflect the extent of underlying inflammation due to differences in perception. The fact that lung function and symptoms may be affected by bronchodilators is particularly important because of a recent trend towards use of the lower doses of inhaled corticosteroids in combination with long-acting $\beta_{2}$-agonists (LABA).

Reproducibility of the standardised FENO measurements according to the ATS standards within a single day in both adults (ICC 0.94) and children (ICC 0.94) is superior to any conventional methods of airway inflammation monitoring in asthma. This adds significantly to other major advantages of FENO measurements, such as their strong association with airway inflammation [2], even in nonsymptomatic asthma patients [26], their high sensitivity to steroid treatment [27], insensitivity to $\beta_{2}$-agonists [2] and noninvasiveness. 
Table 4. - Subjective experience of fractional exhaled nitric oxide measurements with NIOX $\mathbb{R}$

\begin{tabular}{|c|c|c|}
\hline \multirow[t]{2}{*}{ Questions } & \multicolumn{2}{|c|}{ Patients n $(\%)$} \\
\hline & Yes & $\mathrm{No}^{\#}$ \\
\hline $\begin{array}{l}\text { Did you find the information about } \\
\text { the measurements to be adequate } \\
\text { and easy to understand? }\end{array}$ & $60(100)$ & 0 \\
\hline $\begin{array}{l}\text { Did you find it easy to perform the } \\
\text { exhalation manoeuvre as directed } \\
\text { by the investigator and the written } \\
\text { information? }\end{array}$ & $60(100)$ & 0 \\
\hline $\begin{array}{l}\text { Did you experience any form of } \\
\text { discomfort, stress or adverse event } \\
\text { when you were performing the } \\
\text { exhalation manoeuvre? }\end{array}$ & $1(17)^{\bullet}$ & $59(98)$ \\
\hline $\begin{array}{l}\text { If asked, would you accept to do } \\
\text { this examination (three exhalations) } \\
\text { as part of a routine visit to your } \\
\text { doctor if it could be of help in } \\
\text { detecting asthma and selecting } \\
\text { appropriate drug treatment and dosing? }\end{array}$ & $57(95)$ & $3(5)^{+}$ \\
\hline
\end{tabular}

\#: if the answer was "no" subject was asked to specify the reason; ": 11-yr-old asthmatic girl reported mild chest tightness following exhalations; ${ }^{+}$: one child was too young to answer (7-yr-old), the other two (7- and 8-yrs old) answered "do not know".

Repeated FENO measurements, therefore, can be used much more frequently and will not disturb the body system, in contrast to the invasive or semi-invasive procedures currently used in clinical research to monitor inflammation status [2]. The advantage of repetitive FENO measurements has been studied and an increase in FENO and asthma symptoms was seen before any significant deterioration in airway hyperresponsiveness, sputum eosinophils, or lung function during asthma exacerbation induced by steroid reduction [10, 11]. These data suggest that FENO may be used as a loss-of-control-marker in asthma [8]. Recently, it was confirmed that changes in FENO measured over time have higher predictive values, sensitivities, and specificities both for predicting and diagnosing loss of control than did single measurements, which clearly indicates the need for repeated tests [9]. When measured longitudinally the changes in FENO correlated significantly not only with changes in sputum eosinophils and hyperresponsiveness, but also with lung function and asthma symptoms [9].

There are several important practical implications for the FENO measurements regarding the data comparison of spirometry versus FENO examination. Firstly, it has been shown that high reproducibility of FENO measurements in both children and adults may allow the medical practitioner to perform two instead of three exhalations to obtain reliable results (table 2). This may be of great advantage, as it will shorten the time needed for the measurement procedure.

Secondly, FENO measurements with recently developed NO analysers are fully automated and therefore incorrect exhalation manoeuvres by a patient $(<10 \mathrm{~s}$ or outside the limits of the exhaled flow) will not be accepted by the analyser. In addition to the automation, staff training will be minimal. Finally, the advantage of FENO measurements is that patients do not require extra encouragement, as may be the case with PEF measurements. Indeed, a significant difference may be seen between unobserved data and encouraged PEF readings [28].

Bland-Altman analysis of FENO measurements between the sessions separated by either hours or days allowed for the investigation of whether there was a "learning effect" (implying that the subsequent, but not the first FENO measurements are the most reliable). The authors did not find any such "learning effect" or systematic error of serial FENO measurements. The simplicity and high reproducibility of FENO measurements in the present study are probably the major reasons for this. In this study, a single nurse made all the FENO measurements after a short tutorial was given. The simplicity of the standardised FENO measurements was further enhanced by the design of the NO analyser used, which controlled the exhalation parameters and ensured that the measurements were not accepted unless they were performed according to the guidelines [5].

Recently, much greater variability of FENO measurements was shown in 107 healthy children using a different NO analyser when some of the ATS requirements were not fulfilled, for example exhalation flow rate of $184 \mathrm{~mL} \cdot \mathrm{s}^{-1}$ was used instead of $50 \mathrm{~mL} \cdot \mathrm{s}^{-1}$ (ATS standard), nasal clips used (shall not be used according to the ATS standard) and NO free air was not considered [29]. This interesting study demonstrated that although there was no diurnal variation of exhaled NO levels in the studied population, the intra-individual coefficient of variation was rather high $(25.9 \%)$ and the intrameasurement coefficient of variation in a selected group of children was 6.5 $(4.2-8.6) \%$.

The mean pooled SD of all measurements was $2.1 \pm 1.25 \mathrm{ppb}$. These results suggest that if a patient's exhaled FENO level changes $>4$ ppb between sessions, it is more likely due to the inflammatory process rather than inaccuracy of the NO analyser. This finding is valuable for the potential use of FENO in routine clinical practice. Short-term monitoring, when the measurements of airway inflammation are made frequently, for example every day or twice a day as in the case of PEF, is particularly important. This is because of a recent trend towards use of lower doses of inhaled corticosteroids in combination with LABA when anti-inflammatory and clinical effect of combination treatment may be seen within hours and days.

Dose adjustment in both clinical practice and clinical research is an important issue, in which high reproducibility of FENO measurements and sensitivity of FENO to corticosteroids may substantially reduce the cost of medical care and research. Recently, the authors demonstrated a dose-dependent onset and cessation of anti-inflammatory action of inhaled corticosteroids on FENO and asthma symptoms in a small

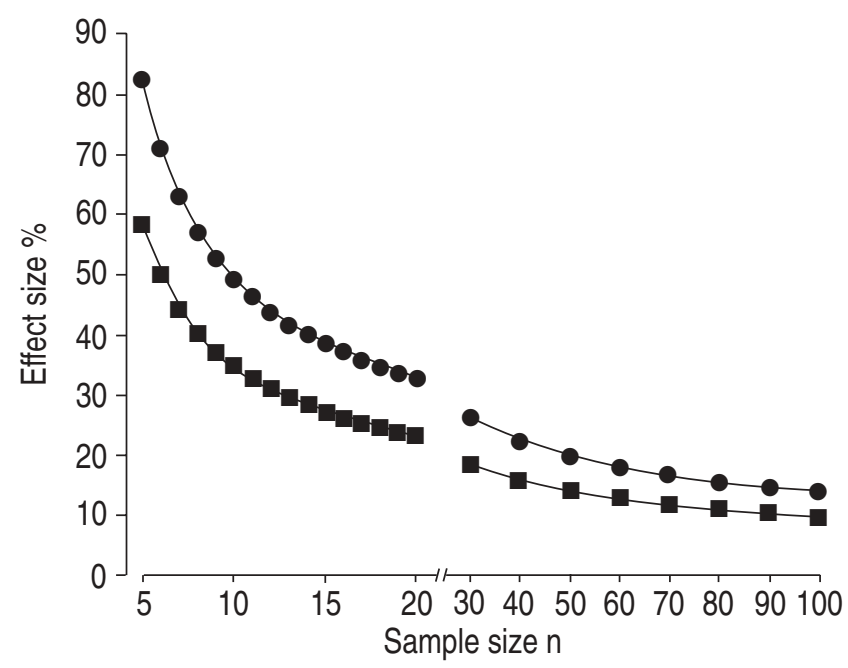

Fig. 3. - The sample size estimates are based on the variability in the outcomes over the two samples (treatment versus placebo $(\bullet)$ ) and one sample (one treatment $(\mathbf{a})$ ) study. 
number $(n=28)$ of mild asthma patients who were treated with 100 or $400 \mu \mathrm{g}$ budesonide, or placebo once daily for 3 weeks in a double-blind, placebo-controlled, parallel group study [7].

Sample-size determination is often an important step in planning such studies. According to the present data (fig. 3), a small number (between 7-20) of asthmatic subjects, either adults or children, will be required to demonstrate $25-80 \%$ effect of a studied drug in a clinical trial. Based on the knowledge of the individual variability of FENO measurements, like individual PEFs, individual FENO values should be established and monitored, and when the levels are above or below a certain reference level, steroid treatment should be either reduced or increased [30].

The data suggest that standardised exhaled nitric oxide measurements may provide a useful clinical tool to monitor airway inflammation in patients with asthma, and acceptable by both healthy and asthmatic adults and children, as a part of their routine visit to a physician. Long-term prospective clinical studies are now necessary to prove that exhaled nitric oxide can be used to optimise dosing of anti-inflammatory treatment.

\section{References}

1. Kharitonov SA, Barnes PJ. Exhaled markers of pulmonary disease. Am J Respir Crit Care Med 2001; 163: 1693-1722.

2. Nightingale JA, Rogers DF, Barnes PJ. Effect of repeated sputum induction on cell counts in normal volunteers. Thorax 1998; 53: 87-90.

3. Fahy JV, Boushey HA, Lazarus SC, et al. Safety and reproducibility of sputum induction in asthmatic subjects in a multicenter study. Am J Respir Crit Care Med 2001; 163 : $1470-1475$.

4. Kharitonov SA, Yates DH, Robbins RA, Logan-Sinclair R, Shinebourne EA, Barnes PJ. Increased nitric oxide in exhaled air of asthmatic patients. Lancet 1994; 343: 133-135.

5. Anonymous. Recommendations for standardized procedures for the online and offline measurement of exhaled lower respiratory nitric oxide and nasal nitric oxide in adults and children. Am J Respir Crit Care Med 1999; 160: 2104-2117.

6. Kharitonov SA, Alving K, Barnes PJ. Exhaled and nasal nitric oxide measurements: recommendations. Eur Respir $J$ 1997; 10: 1683-1693.

7. Kharitonov SA, Donnelly LE, Montuschi P, Corradi M, Collins JV, Barnes PJ. Dose-dependent onset and cessation of action of inhaled budesonide on exhaled nitric oxide and symptoms in mild asthma. Thorax 2002; 57: 889-896.

8. Kharitonov SA. Exhaled nitric oxide and carbon monoxide in asthma. Eur Respir J 1999; 9: 212-218.

9. Jones SL, Kittelson J, Cowan JO, et al. The predictive value of exhaled nitric oxide measurements in assessing changes in asthma control. Am J Respir Crit Care Med 2001; 164: 738743.

10. Kharitonov SA, Yates DH, Chung KF, Barnes PJ. Changes in the dose of inhaled steroid affect exhaled nitric oxide levels in asthmatic patients. Eur Respir J 1996; 9: 196-201.

11. Jatakanon A, Lim S, Barnes PJ. Changes in sputum eosinophils predict loss of asthma control. Am J Respir Crit Care Med 2000; 161: 64-72.

12. Purokivi M, Randell J, Hirvonen MR, Tukiainen $H$. Reproducibility of measurements of exhaled NO, and cell count and cytokine concentrations in induced sputum. Eur Respir J 2000; 16: 242-246.
13. Salome CM, Roberts AM, Brown NJ, Dermand J, Marks GB, Woolcock AJ. Exhaled nitric oxide measurements in a population sample of young adults. Am J Respir Crit Care Med 1999; 159: 911-916.

14. Kharitonov SA, Chung FK, Evans DJ, O'Connor BJ, Barnes PJ. The elevated level of exhaled nitric oxide in asthmatic patients is mainly derived from the lower respiratory tract. Am J Respir Crit Care Med 1996; 153: 1773-1780.

15. Faul JL, Demers EA, Burke CM, Poulter LW. The reproducibility of repeat measures of airway inflammation in stable atopic asthma. Am J Respir Crit Care Med 1999; 160: $1457-1461$.

16. Ames MH. More on the means comparison with unequal variances problem. J Biopharm Stat 1996; 6: 177-183.

17. O'Neil ME, Mathews KL. Levene tests of homogeneity of variance for general block and treatment designs. Biometrics 2002; 58: 216-224.

18. Silkoff PE, McClean P, Spino M, Erlich L, Slutsky AS, Zamel N. Dose-response relationship and reproducibility of the fall in exhaled nitric oxide after inhaled beclomethasone dipropionate therapy in asthma patients. Chest 2001; 119: 1322-1328.

19. Inman MD, Hamilton AL, Kerstjens HA, Watson RM, $\mathrm{O}^{\prime}$ Byrne PM. The utility of methacholine airway responsiveness measurements in evaluating anti-asthma drugs. J Allergy Clin Immunol 1998; 101: 342-348.

20. Omland, Miller MR, Sigsgaard T, Pedersen OF. The shortterm repeatability of histamine bronchial testing in young males. The SUS study. Respir Med 2001; 95: 287-291.

21. Upton MN, Ferrell C, Bidwell C, et al. Improving the quality of spirometry in an epidemiological study: The RenfrewPaisley (Midspan) family study. Public Health 2000; 114: 353-360.

22. den Otter JJ, Bruyn-Schmidt MA, Wolters MJ, et al. Lung function measurement in general practice. General practice measurements compared with laboratory measurements during the DIMCA trial. Fam Pract 2000; 17: 314-316.

23. Ross S, Cochran DP. Method for manipulating peak flow measurements producing falsely raised readings. Thorax 2001; 56: 500-501.

24. Godfrey S. Monitoring asthma severity and response to treatment. Respiration 2001; 68: 637-648.

25. Kamps AW, Roorda RJ, Brand PL. Peak flow diaries in childhood asthma are unreliable. Thorax 2001; 56: 180-182.

26. van Den Toorn LM, Prins JB, Overbeek SE, Hoogsteden $\mathrm{HC}$, de Jongste JC. Adolescents in clinical remission of atopic asthma have elevated exhaled nitric oxide levels and bronchial hyperresponsiveness. Am J Respir Crit Care Med 2000; 162: 953-957.

27. Kharitonov SA, Yates DH, Barnes PJ. Inhaled glucocorticoids decrease nitric oxide in exhaled air of asthmatic patients. Am J Respir Crit Care Med 1996; 153: 454- 457.

28. Gannon PF, Belcher J, Pantin CF, Burge PS. The effect of patient technique and training on the accuracy of self-recorded peak expiratory flow. Eur Respir J 1999; 14: 28-31.

29. Philipp L, Julia B, Matthias G. Exhaled nitric oxide in healthy children: Variability and a lack of correlation with atopy. Pediatr Allergy Immunol 2002; 13: 37-46.

30. Kharitonov SA, Barnes PJ. Does exhaled nitric oxide reflect asthma control? Yes, it does! Am J Respir Crit Care Med 2001; 164: 727-728. 